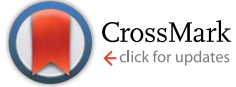

Cite this: J. Mater. Chem. A, 2014, 2 , 14896

\title{
A universal method to form the equivalent ohmic contact for efficient solution-processed organic tandem solar cells $\uparrow$
}

\author{
Ning Li, ${ }^{\star a}$ Tobias Stubhan, ${ }^{a}$ Johannes Krantz, ${ }^{a}$ Florian Machui, ${ }^{a}$ Mathieu Turbiez, \\ Tayebeh Ameri $^{\mathrm{a}}$ and Christoph J. Brabec ${ }^{\mathrm{ac}}$
}

\begin{abstract}
The highly transparent, conductive and robust intermediate layer (IML) is the primary challenge for constructing efficient organic tandem solar cells. In this work, we demonstrate an easy but generic approach to realize the fully functional, solution-processed IMLs. In detail, solution-processed silvernanowires are packed at low concentration between hole- and electron-transporting layers to convert an otherwise rectifying interface into an ohmic interface. The IMLs are proven to be of ohmic nature under applied bias, despite the unipolar charge selectivity of the single layers. Ohmic recombination within IMLs is further proven in organic tandem solar cells fabricated by doctor-blading under ambient conditions. The tandem solar cells based on PCDTBT:[70]PCBM as the bottom cell and pDPP5T-2:[60] PCBM as the top cell give a power conversion efficiency of $7.25 \%$, which is among the highest values for solution-processed organic tandem solar cells fabricated by using a roll-to-roll compatible deposition method in air.
\end{abstract}

Received 23rd June 2014 Accepted 11th July 2014

DOI: $10.1039 / c 4 t a 03182 b$

www.rsc.org/MaterialsA concept, which stacks two or more cells with complementary absorption spectra in series or parallel connection. This concept addresses both losses: the $J_{\mathrm{sc}}$ related absorption losses as well as the $V_{\text {oc }}$ related thermalization losses. In the last few years, a number of organic tandem solar cells with high efficiencies were reported, ${ }^{\mathbf{8 1 5}-22}$ and the efficiency roadmap for tandem cells is clearly pointing towards the predicted $15 \% .^{23}$

To realize high performance organic tandem solar cells, an efficient and reliable intermediate layer (IML) is required, which is typically designed from a series-connected sequence of a holetransporting layer (HTL) and an electron-transporting layer (ETL). ${ }^{22}$ The performance of an organic tandem solar cell is strongly dependent on the quality and functionality of its IML. Ideally, the IML should be highly transparent, conductive and robust enough to protect the underlying semiconductor layer and to form a quasi ohmic contact between HTL and ETL. ${ }^{24}$ The majority of novel active layer materials are sensitive to humidity and oxygen at elevated temperatures and the microstructure of the semiconductor layer might be negatively influenced by the high temperature processing. ${ }^{25}$ Therefore the fabrication of efficient organic tandem solar cells including the IML should avoid high temperature steps.

Although many efforts have been made to understand the recombination properties of IMLs, utilizing commonly used buffer layers to form the quasi ohmic contact in a general way is still a problem for solution-processed tandem solar cells. Today's reference materials for the IMLs are poly(3,4-ethylenedioxythiophene):poly(styrenesulfonate) (PEDOT:PSS) for the hole injection and either titanium oxide $(\mathrm{TiOx})^{26}$ or zinc oxide 
$(\mathrm{ZnO})^{8,15-20}$ for the electron injection. Solution-processed p-type metal oxides, such as vanadium pentoxide $\left(\mathrm{V}_{2} \mathrm{O}_{5}\right),{ }^{27,28}$ molybdenum trioxide $\left(\mathrm{MoO}_{3}\right)^{29,30}$ and tungsten trioxide $\left(\mathrm{WO}_{3}\right)^{31,32}$ were reported as substitutions for the widely used PEDOT:PSS, owing to the comparable device performances but enhanced environmental lifetime for single-junction solar cells. ${ }^{33,34}$ However, the commonly used n- and p-type interface layers, such as PEDOT:PSS and intrinsic metal oxides, do not necessarily form a quasi ohmic contact, especially for the direct contact between metal oxides and metal oxides. Although several groups reported the necessity to thermally-evaporate an ultra-thin metal layer $(\mathrm{Au}, \mathrm{Ca}$, or $\mathrm{Al})$ between the HTL and $\mathrm{ETL},{ }^{35-37}$ the combination of solution processing with vacuum processing is unattractive for up-scaling and low-cost fabrication. Moreover, the mandatory oxygen plasma or ozone pretreatment activation, specifically relevant for many current p-type metal oxides like $\mathrm{MoO}_{3}$ or $\mathrm{NiO}$, is incompatible with tandem processing. ${ }^{29,38}$

Nowadays, solution-processed IMLs reported by several research groups were mainly based on highly conductive PEDOT:PSS, which were exclusively modified to certain n-type interface layers, such as $\mathrm{ZnO}$, to form the quasi ohmic contact. $^{8,15-20}$ Solution-processed $\mathrm{ZnO}$ nanoparticles (ZnO-np) are not well defined in terms of their electrical and semiconducting properties (density of states and density of charge carriers) and may differ for various processes and routes. ${ }^{24,39}$ Moreover, the chemical nature and the density of the ligand groups terminating the surface of ZnO-np, which is essential for contact/interface formation, is very difficult to assess and not known for most systems.

Low-temperature solution-processed metallic nanowires were recently reported as a promising transparent electrode and a potential substitute for the sputtered ITO and the thermally-evaporated top electrode. ${ }^{40-43}$ Metallic nanowire electrodes impress with high conductivity and high transparency, coupled with ease of manufacture. In this manuscript we demonstrate an easy but generic approach to fully solutionprocess efficient IMLs at fairly low temperatures $\left(\leq 80{ }^{\circ} \mathrm{C}\right)$. In detail, a solution-processed thin silver-nanostructure layer, coated from highly diluted silver-nanowire (AgNW) solution between the p-type and n-type charge transporting layers, is able to form an ohmic recombination contact between otherwise non-ohmic semiconductors. The generic approach of this concept is verified by two very different HTL/ETL recombination layers, on the one hand a PEDOT:PSS/ZnO-np layer and on the other hand a $\mathrm{WO}_{3} / \mathrm{ZnO}$-np layer. It is again worthwhile to highlight that the fully functional solution-processed IMLs have been reported by several research groups for efficient tandem solar cells, however, the specific interface material requirements as well as the strict processing conditions restricted the reproduction of the reported promising results. Therefore, the universal approach demonstrated in this contribution indicates a way of forming equivalent ohmic contact between arbitrary qualified $\mathrm{n}$ - and p-type interface layers for efficient IMLs, which significantly reduces the workload of screening qualified interface materials for solution-processed organic tandem solar cells.

\section{Results and discussion}

The charge recombination property of IMLs is investigated in the single-junction OPV devices, as illustrated in Fig. 1(a), which gives immediate feedback on the ohmic nature of the IMLs. ${ }^{24,39}$ To match the requirements of the IML for efficient tandem solar cells, the holes and electrons that are selectively extracted by HTL and ETL should efficiently recombine at the interface. In this case, the single-junction devices with the recombination layers are supposed to show the same performance as devices with a single interface layer. ${ }^{24}$ Fig. 1(b) and (c) represent the transmission spectra of the thin layers and chemical structures

(a)

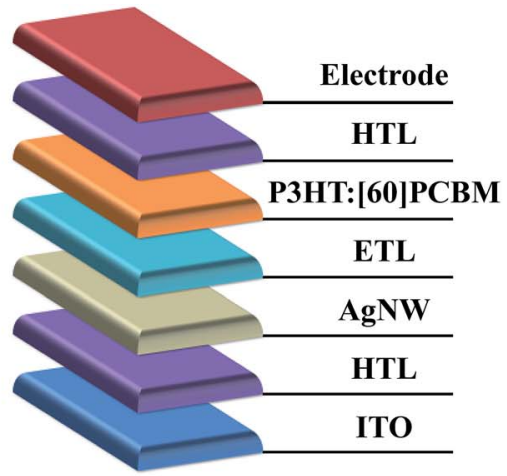

(b)

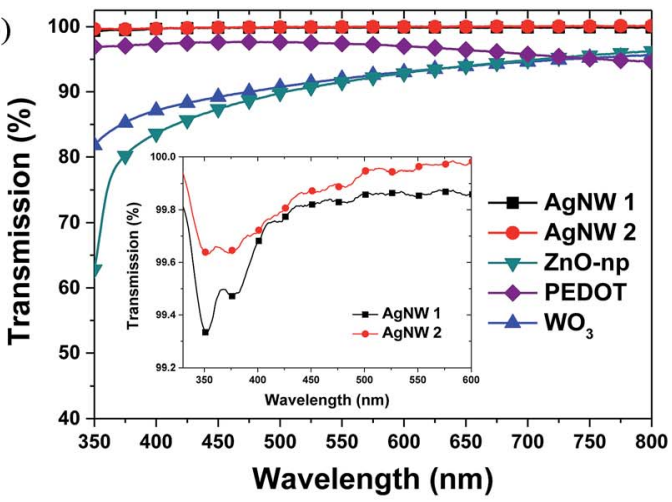

(c)
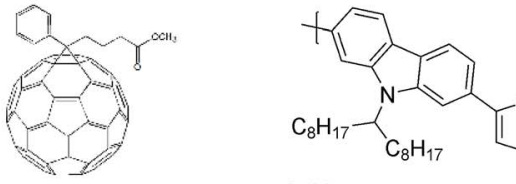

PCDTBT

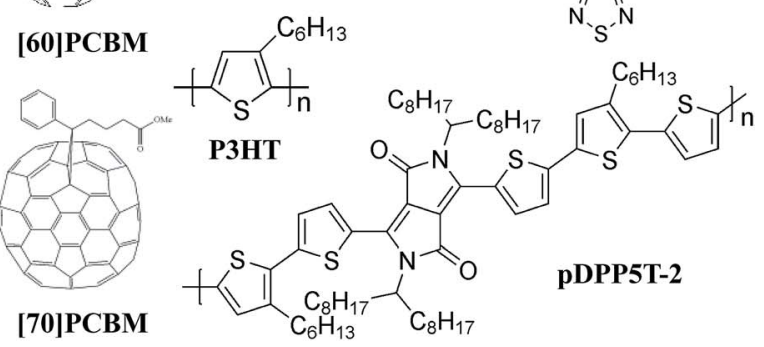

Fig. 1 (a) Architecture of the single-junction solar cells with a solution-processed intermediate layer; (b) transmission spectra of holeand electron-transporting layers. AgNW was diluted in IPA at a volume-ratio of $1: 5$ for AgNW 1 or $1: 10$ for AgNW 2; (c) chemical structures of active materials used in this work. 
of active materials used in this work. PEDOT:PSS AI4083 was purchased from Heraeus and diluted in isopropyl alcohol (IPA) at a volume-ratio of $1: 5$ before processing. ZnO-np were synthesized from zinc acetate ${ }^{44}$ and dissolved in ethanol at $2 \mathrm{wt} \%$. $\mathrm{WO}_{3}$ nanoparticles were synthesized from flame pyrolysis $^{31,32}$ and dissolved at $2.5 \mathrm{wt} \%$ in ethanol. The AgNW ink was prepared from a water based master solution and diluted in IPA at a volume-ratio of $1: 5$ (AgNW 1) or 1:10 (AgNW 2). The AgNW 1 and AgNW 2 are highly transparent, as depicted in Fig. 1(b) inset. In the configuration measured, and after correction of the substrate, transmission values of over $99 \%$ are observed in a wavelength range from 350 to $600 \mathrm{~nm}$. A full analysis of the optical properties of AgNW films is reported elsewhere. ${ }^{40}$ The metal oxides $\mathrm{WO}_{3}$ and $\mathrm{ZnO}$-np absorb in the blue regime, while PEDOT:PSS is more absorbing in the infrared regime. Overall transmission of the charge extraction layers is $>90 \%$.

Poly(3-hexylthiophene):[6,6]-phenyl-C61 butyric acid methyl ester (P3HT:PCBM) with a thickness of $100 \mathrm{~nm}$ was used as an active layer. The $J-V$ characteristics of the corresponding OPV devices are summarized in Fig. 2 and Table 1. As depicted in Fig. 2(a), we find significant limitations for the PEDOT:PSS/ ZnO-np interface. Most obvious is the rather low injection under forward bias, resulting in a low fill factor (FF). Consequently, this recombination layer is not expected to properly work in a tandem configuration. Nevertheless, all these problems can be overcome by employing the solution-processed $\mathrm{Ag}$ nanostructure-based thin layer, which completely lifts the recombination restrictions at the HTL/ETL interface. The organic solar cells incorporating the AgNW-based recombination layer (Devices C and D) exhibit comparable performance with the reference (Device A). As shown in Fig. 2(c), the singlejunction solar cells comprising an IML of $\mathrm{WO}_{3} / \mathrm{ZnO}-\mathrm{np}$

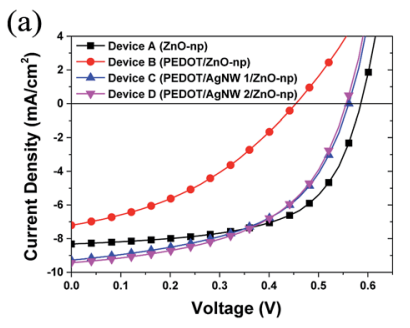

(b)

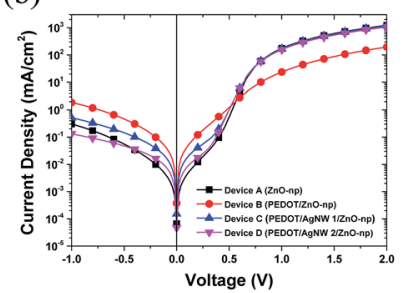

(c)

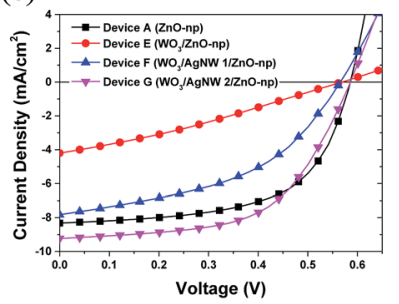

(d)

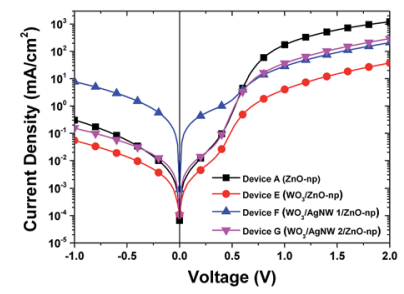

Fig. $2 J-V$ characteristics of single-junction solar cells employing different intermediate layers: (a) and (c) under AM1.5 illumination; (b) and $(d)$ in the dark. Device A: ZnO-np layer; Device B: PEDOT:PSS/ ZnO-np; Device C: PEDOT:PSS/AgNW 1/ZnO-np; Device D: PEDOT:PSS/AgNW 2/ZnO-np; Device E: $\mathrm{WO}_{3} / \mathrm{ZnO}-\mathrm{np} ;$ Device F:

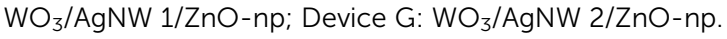

(Device E) suffer from the same deficiencies as the PEDOT:PSS/ ZnO-np devices (Device B), namely low rectification from a high series resistance. Similarly, the performance of the devices utilizing the $\mathrm{WO}_{3} / \mathrm{ZnO}-\mathrm{np}$ IML was again significantly improved by inserting AgNW at the interface. In the case of $\mathrm{WO}_{3}$, a more distinct difference was observed for AgNW 1 versus AgNW 2. Device F, employing the $\mathrm{WO}_{3} / \mathrm{AgNW} 1 / \mathrm{ZnO}-\mathrm{np}$ IML suffers from a significantly higher shunt than Device $\mathrm{G}$ with the $\mathrm{WO}_{3} / \mathrm{AgNW}$ 2/ZnO-np interface. Furthermore, in comparison with the reference devices, the performances of the single-junction solar cells with the HTL/AgNW/ETL injection layer were not affected by the optical losses in the IMLs. In contrast, the single-junction solar cells employing the AgNW-based IML exhibit even slightly higher $J_{\mathrm{sc}}$ compared with the reference device employing a pristine ZnO-np layer, which may be caused by either small variation in the active layer thickness or by a change in the morphological properties of the ZnO-np layer. ${ }^{46,47}$ Summarizing the single-junction devices, it is most relevant to notice that the series resistances $\left(R_{\mathrm{S}}\right)$ of OPV devices, as shown in Table 1, were significantly reduced by inserting AgNW 2 at the interface of the IMLs, while the leakage current was still in the same range as that of reference devices, indicating that the recombination property of the IML was significantly improved by inserting this ultrathin AgNW layer. The nanoparticles, degraded from nanowires, serve even more efficiently as recombination centers at the interface of HTL/ETL compared with nanowires due to their better shunt. Moreover, if several nanowires overlap each other, as shown in Fig. 2(b), this AgNW layer may not be fully covered by overlying $100 \mathrm{~nm} \mathrm{ZnO}-\mathrm{np}$ resulting in high leakage current in the OPV device, which can be observed in the $J-V$ characteristic of Device F.

The synthesis of AgNW is typically based on a polyol process, which requires the presence of a polymeric binder like poly(vinylpyrrolidone) (PVP). PVP as well as other polymeric binders are known to environmentally stabilize the AgNW by efficiently cladding them, and further play an essential role as a matrix in the film formation properties. ${ }^{45}$ The morphologies of AgNWbased IMLs were studied by atomic force microscopy (AFM), as shown in Fig. 3(a)-(i). We observed that the formation of the doctor-bladed AgNW layer is strongly affected by the underlying layer. The formation of AgNW coated on top of $\mathrm{WO}_{3}$ nanoparticles is comparable to that on glass. In contrast, the formation of AgNW will be strongly affected by the underlying PEDOT:PSS layer. The water-IPA-based AgNW solution most likely partially dissolves the PEDOT:PSS layer in the interface, resulting in a mixture of nanowires and nanoparticles. Fig. 3(j) depicts the height value along the line in Fig. 3(b), indicating that the thickness of the polymeric binder is around $10 \mathrm{~nm}$ and the diameters of silver nanowires are $\sim 30 \mathrm{~nm}$.

This picture changes completely for highly diluted AgNW solution. Increasing the dilution with IPA to $1: 10 \mathrm{vol} \%$ results in a nanoparticular coating, which originates from completely degraded AgNWs. Fig. 3(k) depicts the height distributions calculated from the whole area $\left(10 \times 10 \mu \mathrm{m}^{2}\right)$ of Fig. $3(\mathrm{~b})$ and (e). The curves present that the height distributions of nanowires (AgNW 1: full square) and nanoparticles (PEDOT:PSS/ AgNW 1: full circle) are between $10-60 \mathrm{~nm}$ and 30-80 $\mathrm{nm}$ 
Table 1 Photovoltaic parameters of single-junction solar cells employing different interlayers. $R_{\mathrm{s}}$ and $R_{\mathrm{p}}$ were calculated from the corresponding $\mathrm{J}-\mathrm{V}$ characteristics in the dark at 0 and $2 \mathrm{~V}$, respectively. The photovoltaic parameter distributions of devices $\mathrm{B}-\mathrm{G}$ are summarized in Fig. S1 $\dagger$

\begin{tabular}{|c|c|c|c|c|c|c|c|}
\hline & Interlayer & $V_{\mathrm{oc}}[\mathrm{V}]$ & $J_{\mathrm{sc}}\left[\mathrm{mA} \mathrm{cm}^{-2}\right]$ & $\mathrm{FF}[\%]$ & PCE $[\%]$ & $R_{\mathrm{s}}\left[\Omega \mathrm{cm}^{2}\right]$ & $R_{\mathrm{p}}\left[\mathrm{k} \Omega \mathrm{cm}^{2}\right]$ \\
\hline Device A & ZnO-np & 0.58 & -8.32 & 61 & 2.92 & 0.82 & 23.95 \\
\hline Device B & PEDOT:PSS/ZnO-np & 0.46 & -7.21 & 37 & 1.24 & 4.61 & 2.32 \\
\hline Device $\mathrm{C}$ & PEDOT:PSS/AgNW 1/ZnO-np & 0.56 & -9.28 & 52 & 2.72 & 0.84 & 5.66 \\
\hline Device D & PEDOT:PSS/AgNW 2/ZnO-np & 0.56 & -9.42 & 51 & 2.72 & 0.93 & 12.52 \\
\hline Device E & $\mathrm{WO}_{3} / \mathrm{ZnO}-\mathrm{np}$ & 0.56 & -4.20 & 30 & 0.70 & 22.10 & 57.31 \\
\hline Device F & $\mathrm{WO}_{3} / \mathrm{AgNw} 1 / \mathrm{ZnO}-\mathrm{np}$ & 0.56 & -7.82 & 46 & 2.03 & 4.25 & 0.43 \\
\hline Device G & $\mathrm{WO}_{3} / \mathrm{AgNW} 2 / \mathrm{ZnO}-\mathrm{np}$ & 0.58 & -9.24 & 58 & 3.10 & 3.01 & 16.71 \\
\hline
\end{tabular}
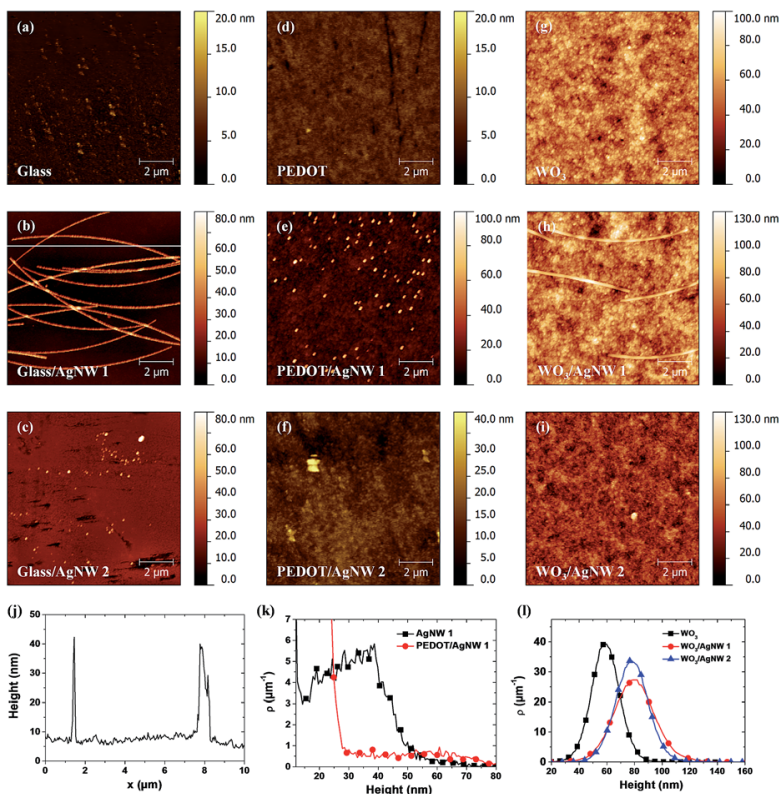

Fig. 3 AFM images of different interface layers (scale bar $2 \mu \mathrm{m}$ ): (a) bare glass; (b) AgNW 1 (1: 5 vol\% in IPA) on glass; (c) AgNW 2 (1: 10 vol\% in IPA) on glass; (d) $50 \mathrm{~nm}$ thick PEDOT:PSS on glass; (e) AgNW 1 on PEDOT:PSS; (f) AgNW 2 on PEDOT:PSS; (g) $60 \mathrm{~nm}$ thick $\mathrm{WO}_{3}$ on glass; (h) AgNW 1 on $\mathrm{WO}_{3}$; (i) $\mathrm{AgNW} 2$ on $\mathrm{WO}_{3}$. (j) Profile analysis extracted from (b), (k) and (l) height distributions calculated from (b), (e) and $(\mathrm{g})-(\mathrm{i})$.

respectively, indicating that the maximal height of AgNW above the polymer film is $\sim 50 \mathrm{~nm}$, which is supposed to be easily covered by the subsequent $100 \mathrm{~nm} \mathrm{ZnO-np.} \mathrm{In} \mathrm{contrast,} \mathrm{the}$ formation of $\mathrm{AgNW}$ on top of the $\mathrm{WO}_{3}$ layer is almost the same as that on glass. The roughness (RMS) of the $\mathrm{WO}_{3}$ layer and $\mathrm{WO}_{3} / \mathrm{AgNW} 2$ were measured to be 6.5 and $8 \mathrm{~nm}$ on average, respectively. The increase in roughness after blading AgNW 2 on top of the $\mathrm{WO}_{3}$ layer shows great accordance to the roughness of the AgNW 2 layer on the glass substrate (2 $\mathrm{nm}$ in average). Additionally, the height distributions of Fig. 3(g)-(i) are calculated from the whole scanning area $\left(10 \times 10 \mu \mathrm{m}^{2}\right)$ and depicted in Fig. 3(1). After blading the AgNWs thin layer on top of $\mathrm{WO}_{3}$ the mean value of the height distributions increased from $\sim 56 \mathrm{~nm}$ to $\sim 80 \mathrm{~nm}$ being in great accordance with the diameters of AgNWs, as shown in Fig. 3(j).

To investigate the functionality of the AgNW-based IML in a real tandem structure, P3HT:PCBM-based tandem solar cells employing different AgNW-based IMLs were constructed. The $J-V$ characteristics of corresponding tandem solar cells are summarized in Fig. S2 and Table S1 By inserting the AgNW between HTL and ETL of the IML, the $V_{\mathrm{oc}}$ and $\mathrm{FF}$ values of tandem solar cells are significantly improved. The prominent improvements reveal that the AgNW-based IMLs are on the one hand robust enough to protect the underlying active layer from the diffusion of solvents during solution processing of upper layers. On the other hand, these IMLs are also efficient enough to collect the charge carriers selectively from subcells. It is worthwhile to notice that in our case the combination of PEDOT:PSS/ZnO-np is not robust enough to serve as an eligible IML in the tandem structure. The polymer-matrix of AgNW is not soluble in the nonpolar solvents. Thus, the stability and reliability of the IML can be enhanced by inserting the AgNW thin layer. Similar improvements were also observed in the tandem devices employing the $\mathrm{WO}_{3} / \mathrm{AgNW}$ 2/ZnO-np intermediate layer. Additionally, tandem solar cells based on the PEDOT:PSS/ AgNW 2/ZnO-np IML shows a series resistance $\left(R_{\mathrm{S}}\right)$ of $1.93 \Omega$ $\mathrm{cm}^{2}$, which is only slightly higher than the sum- $R_{\mathrm{s}}$ of two sub-cells $\left(1.75 \Omega \mathrm{cm}^{2}\right.$ ), indicating that there is almost no extra losses at the interface of this IML. A cross-sectional TEM image of the P3HT:PCBM-based tandem solar cell incorporating the PEDOT:PSS/AgNW/ZnO-np IML is shown in Fig. 4.

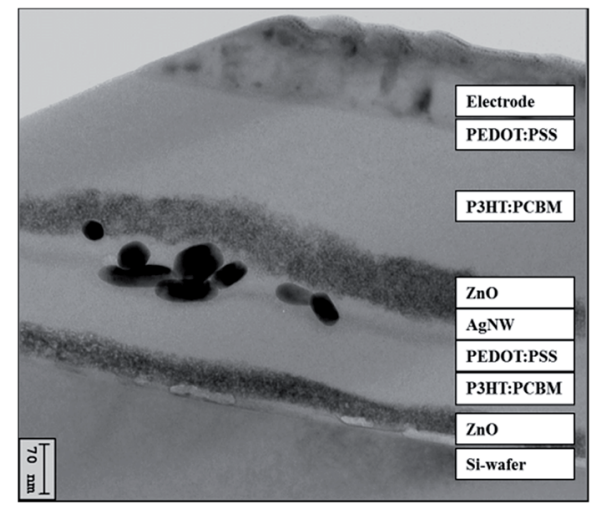

Fig. 4 Cross-sectional TEM image of a P3HT:PCBM-based tandem solar cell incorporating the PEDOT:PSS/AgNW/ZnO-np IML. 
To demonstrate the advantages of the AgNW-based IML on the tandem concept, tandem solar cells based on active layer materials with complementary absorption spectra were constructed. As illustrated in Fig. 5(a), the combination of PEDOT:PSS/AgNW 2/ZnO-np was employed as the IML for tandem solar cells. Poly[ $N$-9"'-hepta-decanyl-2,7-carbazole-alt5,5 -(4' $4^{\prime} 7^{\prime}$-di-2-thienyl-2' $1^{\prime}, 3^{\prime}$-benzothiadiazole)] (PCDTBT) ${ }^{48}$ and a low bandgap diketopyrrolopyrrole-quinquethiophene alternating copolymer (pDPP5T-2) ${ }^{49,50}$ were employed as donor materials. The $J-V$ characteristics of tandem solar cells based on the PCDTBT:[70]PCBM bottom cell and the pDPP5T-2:[60] PCBM top cell, and corresponding reference single cells are summarized in Fig. 5(b) and Table 2. The champion tandem solar cell achieved a $V_{\mathrm{oc}}$ of $1.44 \mathrm{~V}$ along with a $J_{\mathrm{sc}}$ of $8.64 \mathrm{~mA}$ $\mathrm{cm}^{-2}$ and a $\mathrm{FF}$ of $58 \%$ resulting in a PCE of $7.25 \%$, while the corresponding reference solar cells obtained a PCE of 5.55\% and $5.27 \%$ for bottom and top cells respectively. An improvement of $>30 \%$ in PCE was achieved by incorporating both active layers into a tandem structure, indicating on the one hand the advantage of the tandem concept and on the other hand the promising functionality and reliability of the AgNW based IML. The photovoltaic parameters distribution of 6 tandem solar cells (from one substrate) shown in Fig. S3† indicates that $\mathrm{Ag}$ nanoparticles were homogeneously deposited and served identically as recombination centres at the interface of HTL/ETL.

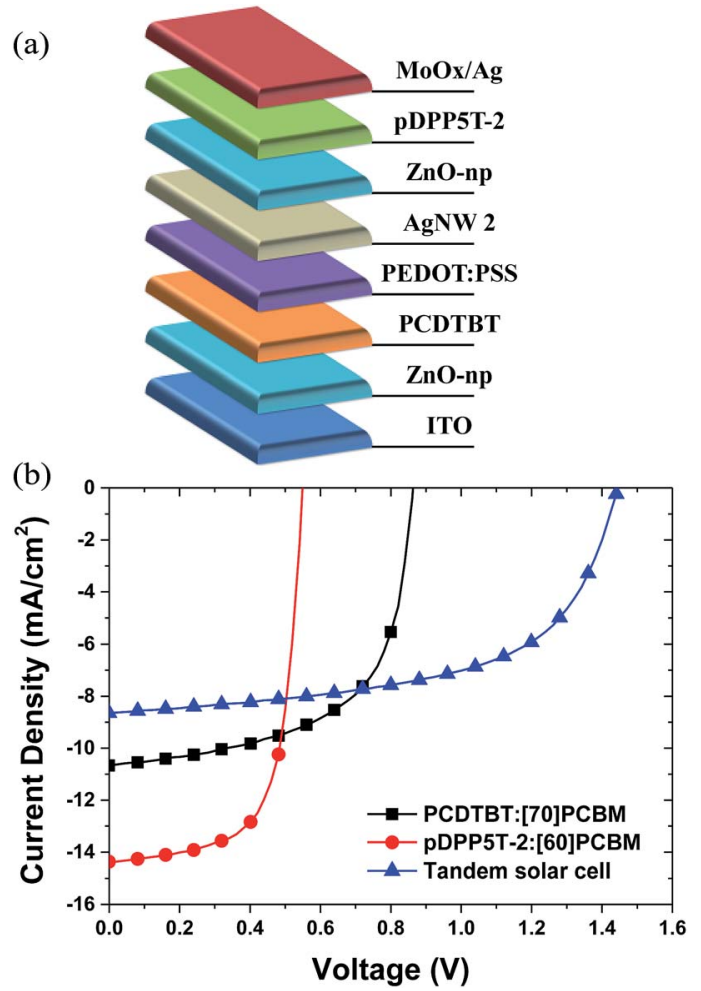

Fig. 5 (a) Device architecture of tandem solar cells employing the AgNW-based IML; (b) J-V characteristics of the tandem solar cell based on the PCDTBT:[70]PCBM bottom cell and the pDPP5T-2:[60] PCBM top cell, and corresponding reference single cells.
Table 2 Photovoltaic parameters of a tandem solar cell based on the PCDTBT:[70]PCBM bottom cell and the pDPP5T-2:[60]PCBM top cell, and corresponding reference single cells. A distribution of photovoltaic parameters over 6 tandem solar cells is shown in Fig. S3†

\begin{tabular}{lllll}
\hline & $V_{\mathrm{oc}}[\mathrm{V}]$ & $J_{\mathrm{sc}}\left[\mathrm{mA} \mathrm{cm}^{-2}\right]$ & $\mathrm{FF}[\%]$ & PCE [\%] \\
\hline Ref. bottom cell & 0.87 & -10.66 & 60 & 5.55 \\
Ref. top cell & 0.55 & -14.37 & 68 & 5.27 \\
Tandem cell & $1.44(1.46)$ & $-8.64(-8.55)$ & $58(58)$ & $7.25(7.24)$
\end{tabular}

\section{Experimental}

\section{Materials}

P3HT $\left(M_{\mathrm{w}}=65.5 \mathrm{~kg} \mathrm{~mol}^{-1}\right)$ and PCDTBT $\left(M_{\mathrm{w}}=127 \mathrm{~kg} \mathrm{~mol}^{-1}\right)$ were purchased from Merck and St-Jean Photochemicals Inc., respectively. [60]PCBM (99.5\%) and [70]PCBM (99\%) were purchased from Solenne BV. PEDOT:PSS (Clevios AI4083) was purchased from Heraeus. Silver-nanowire ink and pDPP5T-2 $\left(M_{\mathrm{w}}=47 \mathrm{~kg} \mathrm{~mol}^{-1}\right)$ were supplied by Cambrios Technology Corporation and BASF, respectively. $\mathrm{WO}_{3}$ nanoparticles suspension (product no. 4035) was provided by Nanograde Llc. ZnO nanoparticles were synthesized in our lab according to previous publications. ${ }^{44}$

\section{Fabrication of single-junction devices}

All the devices were fabricated by doctor-blading under ambient conditions with an architecture shown in Fig. 1(a). Pre-structured ITO-coated glass substrates were cleaned in sequence with acetone and isopropyl alcohol (IPA) for 10 minutes. After drying, the substrates were coated with $50 \mathrm{~nm}$ thick PEDOT:PSS layer or with $60 \mathrm{~nm}$ thick $\mathrm{WO}_{3}$ layer (filtered through a $0.2 \mu \mathrm{m}$ filter before use) and annealed on a hot plate at $80^{\circ} \mathrm{C}$ for $5 \mathrm{~min}$. Afterwards, the AgNW layer (diluted in IPA at 1:5 vol\% for AgNW 1 and $1: 10$ vol\% for AgNW 2) and $\sim 100 \mathrm{~nm}$ thick ZnOnp layer were bladed subsequently and dried at $80{ }^{\circ} \mathrm{C}$ for $5 \mathrm{~min}$ again. An active layer with a thickness of $\sim 100 \mathrm{~nm}$ was bladed from a chlorobenzene solution of P3HT and PCBM with a mixture ratio of $1: 1 \mathrm{wt} \%$. Then, a diluted solution of PEDOT:PSS ( $1: 5 \mathrm{vol} \%$ in IPA) was bladed on top of the active layer. The whole stack was annealed on a hot plate at $140{ }^{\circ} \mathrm{C}$ for 5 min after evaporation of a $100 \mathrm{~nm}$ thick $\mathrm{Ag}$ layer to form the top electrode. For reference, single-junction solar cells based on the ZnO-np buffer layer were constructed under the same conditions with an architecture of ITO/ZnO-np/P3HT:PCBM/ PEDOT:PSS/Ag.

\section{Fabrication of tandem solar cells}

Organic tandem solar cells were fabricated by doctor-blading under ambient conditions with an architecture shown in Fig. 5(a). Pre-cleaned ITO coated glass substrates were coated with $\sim 50 \mathrm{~nm}$ thick ZnO-np and dried at $80{ }^{\circ} \mathrm{C}$ for $5 \mathrm{~min}$. PCDTBT:[70]PCBM (1:4 wt\% dissolved in dichlorobenzene at a total concentration of $20 \mathrm{mg} \mathrm{mL}^{-1}$ ) with a thickness of $\sim 80 \mathrm{~nm}$ was bladed on top of ZnO-np. After that, the IML of PEDOT:PSS/ AgNW 2/ZnO-np was bladed on top of the active layer under the 
same conditions as used for single-junction devices. The second active layer of pDPP5T-2:[60]PCBM $(1: 2 \mathrm{wt} \%$ dissolved in a solvent mixture of $95 \mathrm{vol} \%$ chloroform and $5 \mathrm{vol} \%$ dichlorobenzene at a total concentration of $18 \mathrm{mg} \mathrm{mL}^{-1}$ ) with a thickness of $\sim 100 \mathrm{~nm}$ was deposited. Afterwards, the whole stack was transferred into a nitrogen-filled glovebox. A $15 \mathrm{~nm}$ thick MoOx and a $100 \mathrm{~nm}$ thick $\mathrm{Ag}$ were thermally evaporated in sequence to form the top electrode.

\section{Characterisations}

The active area of OPV devices was defined by the top electrode with a value of $10.4 \mathrm{~mm}^{2}$. The $J-V$ characteristics were measured using a source measurement unit from a BoTest through a mask with an opening of $10.4 \mathrm{~mm}^{2}$. Illumination was provided by a solar simulator (Oriel Sol 1A, from Newport) with AM1.5G spectra at $100 \mathrm{~mW} \mathrm{~cm}^{-2}$. The optical investigations of thin films were carried out by a UV-VIS-NIR spectrometer (Lambda 950, from Perkin Elmer). The thicknesses of films were measured by a profilometer (Tencor Alpha Step D 100). The morphologies of thin films were characterized by AFM (Veeco Model D3100, tapping mode) from the samples prepared on microscopic slides. Samples for cross-sectional TEM were fabricated on a conductive silicon wafer and prepared by focused ion-beam (FIB) sectioning. For FIB sectioning a FEI Strata 235 dual-beam instrument was employed. TEM imaging was performed with an aberration-corrected FEI Titan 80-300. To minimize electronbeam induced damaging of sensitive organic layers the high tension was reduced to $80 \mathrm{kV}^{41}$

\section{Conclusions}

In conclusion, we demonstrated a universal method to fabricate an efficient low-temperature solution-processed IML, in which a solution-processed AgNW-layer was introduced to improve the recombination properties at the interface of the HTL/ETL. Due to the limitation of recombination efficiency, the combination of PEDOT:PSS/ZnO-np and $\mathrm{WO}_{3} / \mathrm{ZnO}-\mathrm{np}$ cannot be directly utilized as efficient IMLs for organic tandem solar cells. By inserting an ultra-thin solution-processed AgNW layer, these IMLs showed a similar functionality with the commonly used single buffer layer in single-junction solar cells, indicating that the equivalent ohmic contact was formed between HTL and ETL. With the improvement of recombination properties, single-junction organic solar cells utilizing the combinations of PEDOT:PSS/ AgNW/ZnO-np as well as $\mathrm{WO}_{3} / \mathrm{AgNW} / \mathrm{ZnO}$-np as IMLs gave PCEs of 2.72 and $3.10 \%$ respectively, while the corresponding cells without AgNW showed PCEs of only 1.24 and $0.70 \%$ respectively. Furthermore, the AgNW-based IMLs were investigated under the same conditions for P3HT:PCBM-based tandem solar cells, suggesting that the combination of PEDOT:PSS/AgNW 2/ZnO-np can serve as an efficient and robust IML for efficient tandem solar cells. To further verify its functionality and reliability, tandem solar cells based on the PCDTBT:[70]PCBM bottom cell and the pDPP5T-2:[60]PCBM top cell were constructed. The tandem solar cell achieved a $V_{\text {oc }}$ of $1.44 \mathrm{~V}$ along with a $J_{\mathrm{sc}}$ of 8.64 $\mathrm{mA} \mathrm{cm}{ }^{-2}$ and a FF of $58 \%$ resulting in a PCE of $7.25 \%$.

\section{Acknowledgements}

The authors thank Dr. Michael Salinas and Prof. Marcus Halik at the Institute of Polymer Materials (LSP) for the access to AFM measurements, and Christel Dieker and Prof. Erdmann Spiecker at the Center of Nanoanalysis and Electron Microscopy (CENEM) for the help with cross-sectional TEM measurements. Cambrios Technology Corporation and Nanograde are acknowledged for providing the silver-nanowire ink and the $\mathrm{WO}_{3}$ nanoparticles suspension, respectively. The authors thank the support of the Cluster of Excellence "Engineering of Advanced Materials" at FAU, which is funded by the German Research Foundation (DFG) within the framework of its "Excellence Initiative", and the support from "Synthetic Carbon Allotropes" (SFB 953) project and "Solar Technologies Go Hybrid" (SolTech) project.

\section{Notes and references}

1 C. J. Brabec, N. S. Sariciftci and J. C. Hummelen, Adv. Funct. Mater., 2001, 11, 15-26.

2 C. J. Brabec, Sol. Energy Mater. Sol. Cells, 2004, 83, 273-292.

3 C. J. Brabec, S. Gowrisanker, J. J. M. Halls, D. Laird, S. Jia and S. P. Williams, Adv. Mater., 2010, 22, 3839-3856.

4 A. J. Heeger, Adv. Mater., 2014, 26, 10-28.

5 F. C. Krebs, N. Espinosa, M. Hösel, R. R. Søndergaard and M. Jørgensen, Adv. Mater., 2014, 26, 29-39.

6 L. Dou, J. You, Z. Hong, Z. Xu, G. Li, R. A. Street and Y. Yang, Adv. Mater., 2013, 25, 6642-6671.

7 M. A. Green, K. Emery, Y. Hishikawa, W. Warta and E. D. Dunlop, Prog. Photovoltaics, 2014, 22, 1-9.

8 J. You, L. Dou, K. Yoshimura, T. Kato, K. Ohya, T. Moriarty, K. Emery, C.-C. Chen, J. Gao, G. Li and Y. Yang, Nat. Commun., 2013, 4, 1446.

9 M. C. Scharber, D. Mühlbacher, M. Koppe, P. Denk, C. Waldauf, A. J. Heeger and C. J. Brabec, Adv. Mater., 2006, 18, 789-794.

10 R. A. J. Janssen and J. Nelson, Adv. Mater., 2013, 25, 18471858.

11 N. Li, F. Machui, D. Waller, M. Koppe and C. J. Brabec, Sol. Energy Mater. Sol. Cells, 2011, 95, 3465-3471.

12 T. Ameri, J. Min, N. Li, F. Machui, D. Baran, M. Forster, K. J. Schottler, D. Dolfen, U. Scherf and C. J. Brabec, Adv. Energy Mater., 2012, 2, 1198-1202.

13 T. Ameri, P. Khoram, J. Min and C. J. Brabec, Adv. Mater., 2013, 25, 4245-4266.

14 L. J. A. Koster, S. E. Shaheen and J. C. Hummelen, Adv. Energy Mater., 2012, 2, 1246-1253.

15 L. Dou, J. You, J. Yang, C.-C. Chen, Y. He, S. Murase, T. Moriarty, K. Emery, G. Li and Y. Yang, Nat. Photonics, 2012, 6, 180-185.

16 L. Dou, W.-H. Chang, J. Gao, C.-C. Chen, J. You and Y. Yang, Adv. Mater., 2013, 25, 825-831.

17 J. Jo, J.-R. Pouliot, D. Wynands, S. D. Collins, J. Y. Kim, T. L. Nguyen, H. Y. Woo, Y. Sun, M. Leclerc and A. J. Heeger, Adv. Mater., 2013, 25, 4783-4788. 
18 C.-Y. Chang, L. Zuo, H.-L. Yip, Y. Li, C.-Z. Li, C.-S. Hsu, Y.-J. Cheng, H. Chen and A. K. Y. Jen, Adv. Funct. Mater., 2013, 23, 5084-5090.

19 W. Li, A. Furlan, K. H. Hendriks, M. M. Wienk and R. A. Janssen, J. Am. Chem. Soc., 2013, 15, 5529-5532.

20 K. Li, Z. Li, K. Feng, X. Xu, L. Wang and Q. Peng, J. Am. Chem. Soc., 2013, 135, 13549-13557.

21 N. Li, D. Baran, G. D. Spyropoulos, H. Zhang, S. Berny, M. Turbiez, T. Ameri, F. C. Krebs and C. J. Brabec, Adv. Energy Mater., 2014, 4, 1400084.

22 T. Ameri, N. Li and C. J. Brabec, Energy Environ. Sci., 2013, 6, 2390-2413.

23 G. Dennler, M. C. Scharber, T. Ameri, P. Denk, K. Forberich, C. Waldauf and C. J. Brabec, Adv. Mater., 2008, 20, 579-583.

24 N. Li, T. Stubhan, D. Baran, J. Min, H. Wang, T. Ameri and C. J. Brabec, Adv. Energy Mater., 2013, 3, 301-307.

25 C. J. Brabec, M. Heeney, I. McCulloch and J. Nelson, Chem. Soc. Rev., 2011, 40, 1185-1199.

26 J. Y. Kim, K. Lee, N. E. Coates, D. Moses, T. Q. Nguyen, M. Dante and A. J. Heeger, Science, 2007, 317, 222-225.

27 H.-Q. Wang, N. Li, N. S. Guldal and C. J. Brabec, Org. Electron., 2012, 13, 3014-3021.

28 K. Zilberberg, S. Trost, H. Schmidt and T. Riedl, Adv. Energy Mater., 2011, 1, 377-381.

29 T. Stubhan, T. Ameri, M. Salinas, J. Krantz, F. Machui, M. Halik and C. J. Brabec, Appl. Phys. Lett., 2011, 98, 253308.

30 K. Zilberberg, H. Gharbi, A. Behrendt, S. Trost and T. Riedl, ACS Appl. Mater. Interfaces, 2012, 4, 1164-1168.

31 T. Stubhan, N. Li, N. A. Luechinger, S. C. Halim, G. J. Matt and C. J. Brabec, Adv. Energy Mater., 2012, 2, 1433-1438.

32 N. Li, T. Stubhan, N. A. Luechinger, S. C. Halim, G. J. Matt, T. Ameri and C. J. Brabec, Org. Electron., 2012, 13, 2479-2484.

33 K. Zilberberg, J. Meyer and T. Riedl, J. Mater. Chem. C, 2013, 1, 4796-4815.

34 S. Chen, J. R. Manders, S.-W. Tsang and F. So, J. Mater. Chem., 2012, 22, 24202-24212.

35 A. Hadipour, B. de Boer, J. Wildeman, F. B. Kooistra, J. C. Hummelen, M. G. R. Turbiez, M. M. Wienk, R. A. J. Janssen and P. W. M. Blom, Adv. Funct. Mater., 2006, 16, 1897-1903.

36 S. Sista, M. H. Park, Z. R. Hong, Y. Wu, J. H. Hou, W. L. Kwan, G. Li and Y. Yang, Adv. Mater., 2010, 22, 380-383.
37 C.-H. Chou, W. L. Kwan, Z. Hong, L.-M. Chen and Y. Yang, Adv. Mater., 2011, 23, 1282-1286.

38 K. X. Steirer, P. F. Ndione, N. E. Widjonarko, M. T. Lloyd, J. Meyer, E. L. Ratcliff, A. Kahn, N. R. Armstrong, C. J. Curtis, D. S. Ginley, J. J. Berry and D. C. Olson, Adv. Energy Mater., 2011, 1, 813-820.

39 N. Li, P. Kubis, K. Forberich, T. Ameri, F. C. Krebs and C. J. Brabec, Sol. Energy Mater. Sol. Cells, 2014, 120, 701-708.

40 J. Krantz, T. Stubhan, M. Richter, S. Spallek, I. Litzov, G. J. Matt, E. Spiecker and C. J. Brabec, Adv. Funct. Mater., 2013, 23, 1711-1717.

41 F. Guo, X. Zhu, K. Forberich, J. Krantz, T. Stubhan, M. Salinas, M. Halik, S. Spallek, B. Butz, E. Spiecker, T. Ameri, N. Li, P. Kubis, D. M. Guldi, G. J. Matt and C. J. Brabec, Adv. Energy Mater., 2013, 3, 1062-1067.

42 J.-Y. Lee, S. T. Connor, Y. Cui and P. Peumans, Nano Lett., 2008, 8, 689-692.

43 C.-C. Chen, L. Dou, R. Zhu, C.-H. Chung, T.-B. Song, Y. B. Zheng, S. Hawks, G. Li, P. S. Weiss and Y. Yang, ACS Nano, 2012, 6, 7185-7190.

44 O. Harnack, C. Pacholski, H. Weller, A. Yasuda and J. M. Wessels, Nano Lett., 2003, 3, 1097-1101.

45 S.-H. Zhang, Z.-Y. Jiang, Z.-X. Xie, X. Xu, R.-B. Huang and L.-S. Zheng, J. Phys. Chem. B, 2005, 109, 9416-9421.

46 C. E. Small, S. Chen, J. Subbiah, C. M. Amb, S.-W. Tsang, T.-H. Lai, J. R. Reynolds and F. So, Nat. Photonics, 2012, 6, 115-120.

47 Z. Liang, Q. Zhang, O. Wiranwetchayan, J. Xi, Z. Yang, K. Park, C. Li and G. Cao, Adv. Funct. Mater., 2012, 22, 2194-2201.

48 S. H. Park, A. Roy, S. Beaupre, S. Cho, N. Coates, J. S. Moon, D. Moses, M. Leclerc, K. Lee and A. J. Heeger, Nat. Photonics, 2009, 3, 297-302.

49 N. Li, D. Baran, K. Forberich, M. Turbiez, T. Ameri, F. C. Krebs and C. J. Brabec, Adv. Energy Mater., 2013, 3, 1597-1605.

50 N. Li, D. Baran, K. Forberich, F. Machui, T. Ameri, M. Turbiez, M. Carrasco-Orozco, M. Drees, A. Facchetti, F. C. Krebs and C. J. Brabec, Energy Environ. Sci., 2013, 6, 3407-3413. 